\title{
COMENTARIO A LA SENTENCIA DE LA AUDIENCIA PROVINCIAL DE MADRID, DE 11 DE MAYO DE 2005. REFLEXIONES SOBRE CLÁUSULAS ABUSIVAS PARA EL DERECHO CHILENO
}

\author{
Cristián AEdo BARrena*
}

\section{INTRODUCCIÓN}

La sentencia que comentamos corresponde a un fallo de segunda instancia, dictado por la Audiencia Provincial de Madrid, sección 13a a el 11 de mayo de 2005, en el recurso de apelación 15/2004. Como tendremos oportunidad de explicar, la cuestión jurídica planteada dice relación con un conjunto, serie o clase de cláusulas consideradas abusivas en las relaciones banco-cliente. Y la sentencia que comentamos, sin duda alguna, aunque dictada hace algunos años en España, nos permitirá reflexionar sobre la regulación de estas materias en Chile, desde que estamos en presencia de un problema de enorme actualidad. Desde un punto de vista político, recientemente hemos visto la promesa de crear una especie de SERNAC financiero y, desde el terreno de la regulación positiva con la que contamos, es interesante su comparación con las cláusulas abusivas reguladas en el artículo 16 de la Ley $\mathrm{N}^{\circ} 19.496$, sobre protección de los consumidores. De este modo, el fallo que comentamos permitirá hacer dos tipos de reflexiones. De un lado, abordar la cuestión de la extensión de la aplicación de la norma positiva chilena que regula esta materia. De otro, pensar en la pertinencia y extensión de las cláusulas mismas, en el supuesto de relaciones banco-cliente.

\section{1) RESUMEN DE LOS HECHOS}

La cuestión jurídica planteada en la sentencia que se comenta, es relativamente simple. En efecto, en la demanda que da origen a los hechos, la Organización de Consumidores y Usuarios interpuso demanda en contra de BBVA, Bankinter S.A., Caja de Ahorros y Monte de Piedad de

Abogado y profesor de Derecho Civil de la Universidad Católica del Norte (CHILE). Diploma de Estudios Avanzados por la Universidad de Deusto (EspañA). Actualmente trabajando en su tesis doctoral en la Universidad de Deusto (España), bajo la dirección del Prof. Dr. Ricardo de Angel YAGÜEZ. Becario del proyecto Mecesup UCN0301 de la Universidad Católica del Norte. 
Madrid y Banco Santander Central Hispano, a objeto que el tribunal de primera instancia declarara la nulidad de diversas cláusulas utilizadas por las referidas entidades bancarias en diversos contratos de adhesión, como de apertura de cuenta corriente, tarjetas de crédito o préstamos hipotecarios, prohibiendo a las referidas entidades bancarias la utilización de tales cláusulas. Se fundaban en que las cláusulas impugnadas vulneraban las disposiciones de la Ley 7/98, sobre condiciones generales de la contratación. Acogida parcialmente la demanda, en primera instancia, por sentencia de 24 de septiembre de 2003, dictada por el 44 Juzgado de $1^{\text {a }}$ instancia de Madrid, en el Juicio Verbal Rol 40/03, ambas partes apelaron ante la Audiencia Provincial de Madrid.

\section{2) ANÁlISIS DE LA SENTENCIA}

La sentencia de segunda instancia puede ser dividida en dos partes para efectos de análisis. En una primera parte resuelve dos excepciones procesales opuestas por las partes demandadas y apelantes. En la primera alegan los apelantes que se han acumulado indebidamente las acciones ejercitadas y que procede su revocación, no bastando el mero supuesto de cláusulas idénticas -cuestión que de plano rechazan-para que proceda la referida acumulación, no siendo suficiente para apreciar la causa de pedir, como lo exige el artículo 72 de la Ley de Enjuiciamiento Civil, pues aun con una redacción parecida, se trata de distintos contratos, destinados a diferentes clientes. La Audiencia rechaza estas pretensiones, por cuanto sostiene que las cláusulas tienen la homogeneidad necesaria para que puedan extenderse a todas ellas los pronunciamientos que se recojan en la resolución judicial que resuelva el litigio. Además sostiene la interpretación flexible de la acumulación, elaborada por diversos fallos del Tribunal Supremo.

La segunda excepción opuesta es la falta de motivación de la sentencia, formulada por BBVA, por cuanto el tribunal no habría explicado las razones por las cuales anulaba cada una de las cláusulas signadas por las letras A, B, C, D, E y H. Al respecto, la Audiencia sostiene, siguiendo la jurisprudencia sentada por el Tribunal Supremo que, refiriéndose a su vez a la doctrina del Tribunal Constitucional, el cual interpretando los artículos 120.3 y 24 de la Constitución espańola, relativa a la tutela judicial efectiva, aun cuando la sentencia de primera instancia no contenga una fundamentación pormenorizada de cada una de la cláusulas analizadas, el examen genérico de la normativa aplicable al caso, recogida en los fundamentos de derecho octavo y noveno e igualmente en el "razonamiento jurídico segundo" del auto aclaratorio, permite considerar suficientemente motivada la resolución contra la que se recurre.

Resueltas estas cuestiones previas, la Audiencia analiza cada una de las cláusulas impugnadas, confirmando o revocado la sentencia de prime- 
ra instancia en cada uno de los casos, haciéndose cargo de las argumentaciones de las partes en sus respectivas apelaciones, de acuerdo al siguiente orden. Solo nos referiremos, brevemente, a aquellas cláusulas que fueron declaradas nulas:

(a) En cuanto a la cláusula sobre falta de información al cliente sobre las tarifas, comisiones y gastos de la cuenta, a la que se refiere en el considerando sexto, confirma la sentencia de primera instancia, que declaró la nulidad de dicha cláusula. La Audiencia rechaza las alegaciones particulares del apelante Caja Madrid, quien sostenía que todo usuario sabe que se le van a cobrar servicios, alegando además que la referida cláusula ya no era utilizada en los contratos por la entidad. El primer argumento se rechaza sosteniendo que no está en cuestión la presunción de onerosidad del contrato, sino la falta de transparencia en la información dirigida al cliente, debiendo entregarse, además del anuncio de cobros, los valores precisos. En cuanto a la no utilización, la Audiencia sostiene que el mantenimiento de la cláusula no garantiza, frente a los demandantes, que en el futuro no pueda volver a emplearse. También rechaza la alegación del BBVA, por cuanto según la entidad la referida cláusula, en los casos de apertura de tarjetas de crédito, pone a disposición de los clientes la información de costes en las oficinas del Banco, de manera que la cláusula no debe ser interpretada aisladamente, sino que en relación a un conjunto contractual. La Audiencia rechaza esta alegación, pues entiende que la cláusula debe bastarse a sí misma, es decir, que por ella misma debe incorporar la información necesaria para el consumidor y que nada obsta que pueda anularse una cláusula subsistiendo el contrato en lo demás.

(b) En cuanto a la cláusula que impone al cliente un fuero territorial especial, a conveniencia de la entidad o sumisión expresa en caso de litigio, a la que se refiere en el considerado séptimo, la Audiencia confirma el fallo de primera instancia que decretó la nulidad de la cláusula. Rechaza la alegación de Caja Madrid, en cuanto esta reitera la no utilización actual de la cláusula. Además, se remite al fundamento utilizado por el fallo de primera instancia, en el sentido de la jurisprudencia del Tribunal Supremo sentada en orden a anular las cláusulas que implican sumisión expresa para el cliente. En cuanto a la alegación de Bankinter, la Audiencia sostiene que la alegación del apelante, quien indica que la redacción de sus cláusulas es distinta a las de sumisión expresa en algunos de sus contratos, es sostenible solo cuando no se ha pactado expresamente la referida sumisión, en cuyo caso la cláusula en cuestión sería nula. En cuanto a la alegación de BBVA, en cuanto a que la sumisión expresa es utilizada en los contratos hipotecarios, sea que la emplee un consumidor o no, 
agregando que el contrato acompańado por la contraria era anterior a la actual Ley de Enjuiciamiento, cuando la normativa permitía en determinados casos la sumisión expresa. Ambos argumentos son rechazados por la Audiencia. El primero, en cuanto la ley otorga expresamente legitimación a los consumidores para dirigir estas acciones (art. 11 Ley de Enjuiciamiento Civil); y, en lo relativo al segundo, que antes de la entrada en vigor de la Ley de Enjuiciamiento Civil la ley ya había resuelto la nulidad de dichas cláusulas en relación con los consumidores, en virtud de los prescrito en el antiguo artículo 10.1 c) de la Ley General para la protección de consumidores y usuarios.

(c) En cuanto a la cláusula que impone al cliente los gastos y costas en caso de litigio, a la que se refiere en el considerado octavo, la Audiencia confirma el fallo de primera instancia que decretó la nulidad de la cláusula. Para el apelante BCSH, la redacción de la cláusula en sus contratos es la simple aplicación del artículo 394 de la Ley de Enjuiciamiento Civil, que establece el principio objetivo del vencimiento, por cuanto se imponen al cliente todos los gastos y costas necesarios para lograr el cumplimiento. La Audiencia rechaza esta alegación, pues en lo que se refiere a la aplicación de las costas judiciales, la referida cláusula impide la aplicación del artículo 394 por parte de los jueces, quienes son los únicos llamados a aplicar la norma y a apreciar la posibilidad de que el cliente no deba pagar las costas frente, cuando concurren serias dudas de hecho o de Derecho que justifiquen su no interposición. Por razones similares, rechaza las alegaciones de Bankinter, Caja Madrid y BBVA.

(d) En cuanto a la cláusula que impone la extensión de responsabilidad de entidad por pérdida, sustracción o manipulación de cheques, a la que se refiere en el considerado undécimo, la Audiencia confirma el fallo de primera instancia que decretó la nulidad de la cláusula. La Audiencia se hace cargo de las alegaciones de Caja Madrid, en orden a que la cláusula no es contraria a la buena fe, no causa desequilibrio entre las partes, pues el cliente queda exento de responsabilidad apenas comunique la situación a la entidad bancaria, toda vez que la referida cláusula no contiene el reparto de obligaciones y derechos alegados por el apelante, en cuanto a que exime de manera general y a priori de responsabilidad a la entidad bancaria, pudiendo ocurrir casos en los que aún sin la comunicación del cliente, la entidad incurra en responsabilidad. Además, Caja Madrid sostiene que no es posible aplicar la disposición adicional primera de la Ley General para la Defensa de Consumidores y Usuarios, por cuanto, en caso de hurto o robo sería víctima de engaño que supone un cheque falso o manipulado y ello nunca podría entenderse como un error administrativo o de gestión. Frente a ello la Audiencia argumenta que la 
doctrina asentada por el Tribunal Supremo que, aplicando el artículo 156 de la Ley Cambiaria y del Cheque, que hace referencia a los cheques falsos o falsificados, estableciendo la responsabilidad del librado en el pago, siempre que el librador no haya actuado con diligencia en la custodia del talonario de cheques. Por las mismas razones rechaza las alegaciones de BBVA y Bankinter, pues contrariamente a lo sostenido por los apelantes, la Audiencia considera que las cláusulas impugnadas no importan un reparto de responsabilidades conforme a la norma citada.

(e) En cuanto a la cláusula que exime de responsabilidad a la entidad por fallos en los aparatos en la realización de operaciones con tarjetas de crédito o débito, a la que se refiere en el considerado decimocuarto, la Audiencia confirma el fallo de primera instancia que decretó la nulidad de la cláusula. El BBVA impugnó el pronunciamiento de primera instancia, al entender que teniendo el mismo fundamento que la séptima, declarada válida por la sentencia, procede dejar sin efecto la decisión del tribunal. Al respecto la Audiencia sostiene que la validez de la cláusula séptima se fundamenta en la amenidad de la entidad bancaria en relación con las operaciones que se practican; en cambio, tratándose de redes de cajeros o terminales de capturas, la responsabilidad derivada del funcionamiento defectuoso es claramente imputable a las entidades bancarias pertenecientes a la misma red concertada, pues aunque no se trate de aparatos de propiedad del banco, se sirva de cajeros ajenos, obteniendo beneficios como el cobro de decisiones y gastos. Por razones similares rechaza las alegaciones de BCSH, Bankinter y Caja Madrid.

(f) En cuanto a la cláusula que permite la resolución anticipada del préstamo por incumplimiento de cualquier prestación por el prestatario, a la que se refiere en el considerado decimoquinto, la Audiencia confirma el fallo de primera instancia que decretó la nulidad de la cláusula. Caja Madrid apela en contra de esa decisión, sosteniendo que no afecta la proporcionalidad, toda vez que otorga a ambas partes el derecho de solicitar la resolución. La Corte entiende que la cláusula no puede tener el sentido genérico que se le asigna, pues sin perjuicio de los casos concretos -en los que resulte notoriamente importante el incumplimiento contractual-, pueda aceptarse la resolución anticipada por el incumplimiento de una obligación de especial relevancia y en ningún caso accesoria. El mismo argumento le lleva a rechazar las alegaciones de Bankinter, BSCH y BBVA.

(g) En cuanto a la cláusula que permite la resolución anticipada al no poder registrar, por cualquier motivo, la hipoteca, a la que se refiere en el considerado decimoctavo, la Audiencia confirma el fallo de primera instancia que decretó la nulidad de la cláusula. Bankinter sostiene la importancia de la hipoteca y el riesgo que asume el banco 
concediendo el importe del préstamo antes que se inscriba la hipoteca. La Audiencia rechaza tales argumentaciones, al estimar que al ser constitutiva la inscripción de la hipoteca, la entidad puede comprobar la viabilidad de la inscripción antes de entregar el préstamo. La omisión de dicha comprobación no es imputable al consumidor. Por razones similares rechaza la alegación de Caja Madrid.

(h) En cuanto a la cláusula de exención e responsabilidad por fallos en el sistema informático (banca telefónica), a la que se refiere en el considerado vigésimo segundo, la Audiencia confirma el fallo de primera instancia que decretó la nulidad de la cláusula. La Audiencia desecha las alegaciones de Bankinter y BBVA por razones similares a las examinadas al desechar las apelaciones tratándose de la cláusula novena.

\section{3) REFLEXIONES PARA EL CASO CHILENO}

Como se puede apreciar, se trata de una sentencia extremadamente compleja, no en términos de los razonamientos jurídicos puestos en cuestión, sino en relación a la naturaleza de las cláusulas cuya nulidad fue declarada por el tribunal de segunda instancia. Puede anotarse que muchas de ellas guardan evidente coincidencia con cláusulas contenidas en contratos bancarios en Chile ${ }^{1}$. En efecto, cláusulas como la falta de información en tarifas, comisiones y gastos; la prórroga de la competencia a conveniencia de la institución financiera y, especialmente, la facultad de poner término anticipado al contrato por incumplimiento del mutuario o por disminución patrimonial del mismo, constituyen cláusulas bastante corrientes en el ámbito de los contratos bancarios.

$\mathrm{La}$ interesante sentencia que comentamos puede sugerirnos dos tipos de reflexiones, que podrán ser desarrolladas brevemente en este comentario. En primer lugar, parece evidente que una comparación con la regulación chilena sobre cláusulas abusivas parece pertinente. Es decir, se trata de examinar si algunas de estas cláusulas, utilizadas en la práctica bancaria chilena, pueden ser consideradas, en algún sentido, cláusulas abusivas. En segundo término, puede abordarse el problema desde una dimensión que juzgamos más profunda, por cuanto uno podría preguntarse si la regulación de las cláusulas abusivas, tal como se ha establecido en el ordenamiento español, como en el chileno, es la idónea o adecuada para atender las razones de justicia y el control de la libertad de las partes, cuando los partícipes de la relación contractual no se encuentran en un plano de igualdad. 
Si atendemos a la primera reflexión propuesta, habrá que comenzar explicando el complejo sistema español sobre estas materias, en parte simplificado por el nuevo texto refundido de la Ley de consumidores y usuarios. En efecto, por un lado encontramos la Ley 7/1998, de 13 de abril de 1998, sobre condiciones generales de la contratación (en adelante LCGC), publicada en el BOE de 14 de abril de 1998, transpuso tardíamente la Directiva 93/13/CEE ${ }^{2}$, de 5 de abril de 1993, sobre cláusulas abusivas celebradas con consumidores y la regulación de las condiciones generales de contratación ${ }^{3}$.

La ley en comento presenta dos partes completamente diferenciadas. Como indica Vicent Chuliá, por un lado encontramos un cuerpo normativo, compuesto de 24 artículos dedicado íntegramente a las condiciones generales de los contratos, tanto entre profesionales, como entre profesionales y consumidores; de otro, una disposición adicional destinada a introducir reformas en la Ley 26/1984, General para la defensa de los consumidores y usuarios. Agrega: "Incorpora asi la Directiva 13/93/CEE, con el régimen de las cláusulas abusivas de los contratos celebrados entre profesionales y consumidores, tanto en los basados en condiciones generales de la contratación (en cuyo caso se aplicará, además, la Ley 7/1998), como en contratos aislados, con tal de que hayan sido redactados e impuestos por el profesional al consumidor, es decir, que sean contratos de adhesión, no negociados,

2 Como explica Vicent Chulí, Francisco (2004): "Condiciones generales de la contratación y condiciones abusivas bancarias", Revista de Derecho patrimonial, 13, p. 54, indica que fue tan tardía dicha incorporación, que la sentencia del TS, de 8 de noviembre de 1996 ya había aplicado directamente la Directiva. Un interesante trabajo en este sentido, es decir, sobre la jurisprudencia que decidió la aplicación directa de la Directiva 13/93/CEE, se encuentra en Blanco Pérez-Rubio, Lourdes (1997), "La posible eficacia directa horizontal de la directiva 93/13 sobre cláusulas abusivas en los contratos celebrados con consumidores (a propósito de las Sentencias del Tribunal Supremo de 8 y 20 de noviembre de 1996), Estudios sobre consumo, 41, pp. 27-47.

3 En cuanto al derecho derivado, suele distinguirse entre las normas típicas o reguladas, que tienen especial importancia para fijar el contexto normativo de este artículo y los actos atípicos o "soft law". Los actos típicos se encuentran regulados principalmente en Capítulo 2 de la sección quinta del Tratado de la Comunidad Europea. El artículo 249, al respecto, dispone: "Para el cumplimiento de su misión, el Parlamento Europeo y el Consejo conjuntamente, el Consejo y la Comisión adoptarán reglamentos y directivas, tomarán decisiones y formularán recomendaciones o emitirán dictämenes, en las condiciones previstas en el presente Tratado. El reglamento tendrá un alcance general. Será obligatorio en todos sus elementos y directamente aplicable en cada Estado miembro. La directiva obligará al Estado miembro destinatario en cuanto al resultado que deba conseguirse, dejando, sin embargo, a las autoridades nacionales la elección de la forma y de los medios. La decisión será obligatoria en todos sus elementos para todos sus destinatarios. Las recomendaciones y los dictámenes no serán vinculantes". En cuanto a los actos atípicos, que han ido surgiendo con la practica institucional, pueden mencionarse los de carácter interno, como los reglamentos internos de las distintas instituciones y órganos (que en muchos casos tienen base normativa, como en los artículos 199, 207 y 218 del Tratado de la CE); actos políticos, como las deliberaciones, las resoluciones del Consejo y las comunicaciones de la Comisión. 
al menos, en su totalidad" ${ }^{4}$. De acuerdo con el mensaje del proyecto de la LCGC: "Una cláusula es condición general cuando está predispuesta e incorporada a una pluralidad de contratos exclusivamente por una de las partes, y no tiene por qué ser abusiva. Cláusula abusiva es la que en contra de las exigencias de la buena fe causa en detrimento del consumidor un desequilibrio importante e injustificado de las obligaciones contractuales y puede tener o no el carácter de condición general, ya que también puede darse en contratos particulares cuando no existe negociación individual de sus cláusulas, esto es, en contratos de adhesión particulares. Las condiciones generales de la contratación se pueden dar tanto en las relaciones de profesionales entre si como de estos con los consumidores. En uno y otro caso, se exige que las condiciones generales formen parte del contrato, sean conocidas o en ciertos casos de contratación no escrita exista posibilidad real de ser conocidas, y que se redacten de forma transparente, con claridad, concreción y sencillez. Pero, además, se exige, cuando se contrata con un consumidor, que no sean abusivas".

Las condiciones generales de contratación, en consecuencia, de acuerdo con lo dispuesto en el artículo 1.1 de la LCGC, son: "Las cláusulas predispuestas cuya incorporación al contrato sea impuesta por una de las partes, con independencia de la autoría material de las mismas, de su apariencia externa, de su extensión y de cualesquiera otras circunstancias, habiendo sido redactadas con la finalidad de ser incorporadas a una pluralidad de contratos". Como se ha advertido precedentemente, las condiciones generales de contratación se aplican tanto a las relaciones entre profesionales, como cuando dicha relación existe entre un profesional y un consumidor. El artículo 2 de la LCGC entiende por profesional, la persona natural o jurídica que se desenvuelve en el marco de su actividad profesional o empresarial, pública o privada. De este modo, como afirma Vicent, se logra la unidad de la regulación de los contratos, pues la ley no atiende a la naturaleza, civil o mercantil del contrato, ni a los sujetos que intervienen en él ${ }^{5}$.

Relacionadas con ellas se encuentran las cláusulas abusivas, entendidas como una especie del género condiciones generales de los contratos. Es bastante claro sobre este punto el artículo 8 de la LCGC, el cual dispone que son nulas de pleno derecho aquellas condiciones que sean consideradas abusivas, cuando el contrato sea celebrado con el consumidor y no se ajusten a lo prescrito en la actual Ley de consumidores y usuarios,

Vicent (2004) 55. Con toda razón el mismo Vicent Chulí́, Francisco (1995), "Doctrina, Ciencia de la legislación e institucionalización del Derecho mercantil en la última década", en AA.VV., Estudios de Derecho Mercantil en homenaje al Profesor Manuel Broseta Pont, Valencia: Tirant lo Blanch, vol. III, pp. 4043 y ss., ha escrito un extenso trabajo destinado a analizar las debilidades de la ciencia jurídica espańola, destacando el caso de la regulación contractual, dispersión que en parte ha pretendido ser solucionada, como veremos, por el texto refundido de la ley de consumidores y usuarios. ViCENT (2004) 55. 
como tendremos oportunidad de analizar. De este modo, con una técnica legislativa bastante compleja, la LCGC introduce en la disposición adicional primera, importantes modificaciones a la Ley 26/1984, de 19 de julio, General para la Defensa de los Consumidores y Usuarios (LGD$\mathrm{CU})$, agrega un artículo 10bis, en el que se definen las cláusulas abusivas y una disposición adicional primera, en la que se enumeran las cláusulas abusivas.

Sin embargo, ha de tenerse presente que el complejo panorama legislativo español fue en parte superado en virtud del Real Decreto $1 / 2007$, de 30 de noviembre de 2007, por el que se aprueba el texto refundido de la Ley General para la defensa de los consumidores y usuarios y otras leyes especiales ${ }^{6}$. Como consecuencia, las cláusulas abusivas pasaron a estar

6 De acuerdo con la exposición de motivos del Real Decreto: "Analizado en anexo de la citada directiva, se integran en el texto refundido de la Ley General para la Defensa de los Consumidores y Usuarios y otras leyes complementarias las normas de transposición de las directivas comunitarias que, dictadas en materia de protección de los consumidores y usuarios, inciden en los aspectos contractuales regulados en la Ley 26/1984, de 19 de julio, General para la Defensa de los Consumidores y Usuarios, y que establecen el régimen juridico de determinadas modalidades de contratación con los consumidores, a saber: los contratos celebrados a distancia y los celebrados fuera de establecimiento comercial. La regulación sobre garantias en la venta de bienes de consumo, constituye transposición de directiva comunitaria que incide en el ámbito de la garantia regulado por la Ley General para la Defensa de los Consumidores y Usuarios, procediéndose, igualmente a su refundición. Asimismo, se incorpora a la refundición la regulación sobre viajes combinados, por tratarse de una norma de transposición de directiva comunitaria que se integra en el acervo comunitario de protección de los consumidores y establece un régimen juridico especifico en la contratación con consumidores no afectado por las normas estatales sectoriales sobre turismo. Además, se incorpora al texto refundido la regulación sobre la responsabilidad civil por daños causados por productos defectuosos, norma de transposición de directiva comunitaria que incide en aspectos esenciales regulados en la Ley General de Defensa de los Consumidores y Usuarios, y que, como de manera unánime reconoce la doctrina y jurisprudencia requiere aclarar y armonizar sus respectivas regulaciones, al objeto de asegurar una adecuada integración entre ellas, superando aparentes antinomias. Otras normas de transposición de las directivas comunitarias citadas en el anexo de la Directiva 98/27/CE, sin embargo, instrumentan regimenes jurídicos muy diversos que regulan ámbitos sectoriales especificos alejados... "Más adelante, se agrega: "En consecuencia, el cumplimiento del mandato contenido en la disposición final quinta de la Ley 44/2006, de 29 de diciembre, de mejora de la protección de los consumidores y usuarios, exige incorporar al texto refundido de la Ley General para la Defensa de los Consumidores y Usuarios y otras leyes complementarias, la Ley 26/1984, de 19 de julio, General para la Defensa de los Consumidores y Usuarios, la Ley 26/1991, de 21 de noviembre, sobre contratos celebrados fuera de los establecimientos mercantiles; la regulación dictada en materia de protección a los consumidores y usuarios en la Ley 47/2002, de 19 de diciembre, de reforma de la Ley de Ordenación del Comercio Minorista, para la transposición al ordenamiento juridico español de la Directiva sobre contratos a distancia; la Ley 23/2003, de 10 de julio, de Garantias en la Venta de Bienes de Consumo, la Ley 22/1994, de 6 de julio, de responsabilidad civil por los daños causados por productos defectuosos; la Ley 21/1995, de 6 de julio, sobre viajes combinados". En efecto, varias leyes se tradujeron en la transposición al Derecho español de varias directivas de la Unión Europea. Nos referimos a la Directiva 97/7/CE, de 20 de mayo de 1997, relativa a la protección de los consumidores en materia de contratos a distancia, incorporada en el Capítulo II -para los productos-y en la Disposición adicional $1^{\text {a }}$-para los servicios- de la Ley 7/1996, de 15 de enero, de ordenación del comercio minorista, modificada por la Ley 47/2002, de 19 de diciembre (LOCM). En segundo lugar, la Directiva 2000/31/CE, de 8 
reguladas en el Capítulo II, relativa a las cláusulas abusivas, del Título II, relativa a las condiciones generales y cláusulas abusivas, artículos 82 y siguientes. Desde acá podrán hacerse las comparaciones entre el régimen español, la sentencia que comentamos y el sistema chileno.

El actual artículo 82.1 dispone: "1. Se considerarán cláusulas abusivas todas aquellas estipulaciones no negociadas individualmente y todas aquellas prácticas no consentidas expresamente que, en contra de las exigencias de la buena fe causen, en perjuicio del consumidor y usuario, un desequilibrio importante de los derechos y obligaciones de las partes que se deriven del contrato". Se mantiene, de este modo, la misma definición contenida en la reforma introducida a la Ley 26/1984, por la LCGC, en el artículo 10bis.1.

Además, como se ha dicho, la disposición adicional primera introducida en la Ley 26/1984 se dispone de un catálogo o listado de cláusulas abusivas. En esta parte, existe una evidencia notoria con el nuevo texto refundido de la LGDCU. En principio, el actual artículo 82.4 prescribe: "No obstante lo previsto en los apartados precedentes, en todo caso son abusivas las cláusulas que, conforme a lo dispuesto en los artículos 85 a 90, ambos inclusive: a) vinculen el contrato a la voluntad del empresario, b) limiten los derechos del consumidor y usuario, c) determinen la falta de reciprocidad en el contrato, d) impongan al consumidor y usuario garantías desproporcionadas o le impongan indebidamente la carga de la prueba, e) resulten desproporcionadas en relación con el perfeccionamiento y ejecución del contrato, o f) contravengan las reglas sobre competencia y derecho aplicable". Aún así, los artículos 85, 86, 87, 88, 89, 90 y 91 repiten el listado contenido en la disposición adicional primera de la Ley 26/1984, en sus números I (artículo 85); II (artículo 86); III (artículo 87); IV (artículo 88); V (artículos 89,90 y 91 ).

Analizado el complejo panorama legislativo español, podemos referirnos, por vía ejemplar, a algunas de las cláusulas declaradas nulas por la sentencia comentada y luego las compararemos con las denominadas cláusulas abusivas reguladas en nuestro sistema. Así, por ejemplo, la cláusula que impone al cliente un fuero territorial especial, a conveniencia de la entidad o sumisión expresa en caso de litigio, fue declarada nula conforme a lo dispuesto en el apartado 27 de la disposición adicional primera introducida por la LCGC: "La previsión de pactos de sumisión expresa a Juez o Tribunal distinto del que corresponda al domicilio del consumidor, al lugar del cumplimiento de la obligación o aquel en que se encuentre el bien

de junio de 2000, relativa a algunos aspectos de la sociedad de servicios de la información, incorporada por la Ley 34/2002, de 11 de julio, sobre sociedad de servicios de la información y comercio electrónico (en adelante LSSI). Por último, la Directiva 2002/58/CE, de 12 de julio, sobre protección de datos en la contratación electrónica, incorporada en algunas normas de la Ley General de Telecomunicaciones (LGT), presentando entre ellas zonas de común influencia. 
si fuera inmueble, así como los de renuncia o transacción respecto al derecho del consumidor a la elección de fedatario competente según la Ley para autorizar el documento al o ulteriormente haya de formalizarse el contrato", hoy contenida en el artículo 90.2 de la Ley 1/2007. Otra interesante cláusula que se ha declarado nula, es aquella por la cual se impone la extensión de responsabilidad de entidad por pérdida, sustracción o manipulación de cheques, de acuerdo con lo prescrito en el numeral 21 de la disposición adicional primera, es decir: "La transmisión al consumidor de las consecuencias económicas de errores administrativos o de gestión que no le sean imputables", hoy artículo 89, numeral 2.

De inmediato se impone una comparación con la Ley $\mathrm{N}^{\circ} 19.496$, pues el artículo 16 del ordenamiento chileno contempla una enumeración muchísimo más exigua de cláusulas abusivas ${ }^{7}$. Se trata, en consecuencia, de una lista cerrada, pero que admite una interpretación amplia en la letra g), al reconocer la posibilidad de considerar abusiva una cláusula en términos generales, por violación de la buena fe. Hemos propuesto los dos ejemplos precedentes, puesto que el primero, no se encuentra expresamente recogido en el artículo 16, mientras que el segundo podría admitir derechamente la nulidad, en el supuesto establecido en la letra c), cuya redacción es muy similar a la del ordenamiento español, al considerar abusiva la cláusula que pone a cargo del consumidor las omisiones u errores administrativos.

La cuestión está en determinar si en estas materias, es decir, en las relaciones entre el banco o institución financiera y el cliente, pueden aplicarse las normas de la Ley $\mathrm{N}^{\circ} 19.496$. En principio, el artículo 2bis, introducido por la Ley $\mathrm{N}^{\circ} 19.955$, de 14 de julio de 2004, prescribe que, sin perjuicio de las materias en las que expresamente se aplica la

\footnotetext{
Dichas cláusulas son las siguientes: a) Otorguen a una de las partes la facultad de dejar sin efecto o modificar a su solo arbitrio el contrato o de suspender unilateralmente su ejecución, salvo cuando ella se conceda al comprador en las modalidades de venta por correo, a domicilio, por muestrario, usando medios audiovisuales, $u$ otras análogas, $y$ sin perjuicio de las excepciones que las leyes contemplen; b) Establezcan incrementos de precio por servicios, accesorios, financiamiento o recargos, salvo que dichos incrementos correspondan a prestaciones adicionales que sean susceptibles de ser aceptadas o rechazadas en cada caso y estén consignadas por separado en forma especifica; c) Pongan de cargo del consumidor los efectos de deficiencias, omisiones o errores administrativos, cuando ellos no le sean imputables; d) Inviertan la carga de la prueba en perjuicio del consumidor; e) Contengan limitaciones absolutas de responsabilidad frente al consumidor que puedan privar a este de su derecho a resarcimiento frente a deficiencias que afecten la utilidado finalidad esencial del producto o servicio; $f$ ) Incluyan espacios en blanco, que no hayan sido $a, b$ y c) llenados o inutilizados antes de que se suscriba el contrato, $y \mathrm{~g}$ ) En contra de las exigencias de la buena fe, atendiendo para estos efectos a parámetros objetivos, causen en perjuicio del consumidor, un desequilibrio importante en los derechos y obligaciones que para las partes se deriven del contrato. Para ello se atenderá a la finalidad del contrato y a las disposiciones especiales o generales que lo rigen. Se presumirá que dichas cláusulas se encuentran ajustadas a exigencias de la buena fe, si los contratos a que pertenecen han sido revisados y autorizados por un órgano administrativo en ejecución de sus facultades legales.
} 
ley del consumidor, no resulta aplicable a las actividades de producción, fabricación, importación, construcción, distribución y comercialización de bienes o prestación de servicios regulados en leyes especiales. Como indica Sandoval: "Se trata de actividades mercantiles que están sujetas a una normativa especial, como ocurre por ejemplo con la actividad bancaria, financiera, cambiaria, de intermediación de valores, de seguros, de medios de comunicación escritos, radiales o televisivos, de telecomunicaciones, de transporte aéreo, etc."

No obstante, en las materias que las leyes especiales no prevean, como ocurre precisamente en las relaciones entre el banco y el cliente derivadas de los derechos establecidos a favor de los consumidores, es aplicable, en carácter supletorio, las normas de la Ley $\mathrm{N}^{\circ} 19.496$. Concretamente, en lo relativo a las cláusulas abusivas, las relaciones entre los bancos y sus clientes, siempre que sean consumidores, deben ajustarse a las normas de la ley. Así lo señala, por lo demás, expresamente Sandoval: "Sin embargo, en las materias que estas leyes especiales no contemplan, como por ejemplo, publicidad, contratos de adhesión, organización de consumidores, promociones, ofertas e información, son aplicables las reglas de la ley de protección de los derechos del consumidor" ". Otro problema, sin embargo, es la aplicabilidad de tales cláusulas y los problemas que se han planteado en su interpretación ${ }^{10}$.

Pizarro, efectivamente, ha apuntado a la falta de aplicación y control de las cláusulas abusivas, a la ausencia casi total de jurisprudencia sobre el problema. Sin embargo, nuestro comentario debería conducirnos a ensayar, al menos preliminarmente, otra crítica, de la que no se ha hecho eco la dogmática chilena. En efecto, la existencia de cláusulas abusivas solo en el ámbito de las relaciones de consumo, hace aún más graves los problemas de aplicación y desfavorece la creación de pequeńas y medianas empresas, que se encuentran doblemente gravadas, por lo que Vicent Chuliá

SANDoval López, Ricardo (2004): Las reformas introducidas por la Ley $N^{\circ} 19.955$, de 14 de julio de 2004 a la Ley $N^{\circ} 19.496$, sobre protección de los derechos de los consumidores, Santiago: LexisNexis, p. 26.

9 SANDOVAL (2004) 26-27.

10 Para esta cuestión, véase el interesante e ilustrativo trabajo de campo, del que se extraen consecuencias dogmática, de Pizarro Wilson, Carlos (2007): "El fracaso de un sistema. Análisis empírico y dogmático del control de cláusulas abusivas en contratos por adhesión", Revista de Derecho, vol. XX, 2 pp. 31-47. Su conclusión es bastante categórica: "Expuestas las sentencias más relevantes, se constata que el ámbito en que incide el control de cláusulas abusivas es muy reducido. Aún más, las temáticas en que se han pronunciado los juzgados de Policia Local impiden extraer conclusiones generales. Con todo, puede aseverarse que existe una total falta de uniformidad en la solución de los problemas atingentes a las cláusulas abusivas. Que el articulado del articulo 16 es poco utilizado, incluso con un predominio absoluto de la letra b) que impide la modificación unilateral del contrato por el proveedor. Por lo demás, en varias sentencias la fuerza obligatoria del contrato justifica rechazar las pretensiones de los consumidores, debiendo entenderse este principio atenuado por la ley de protección al consumidor y, con mayor razón, con la modificación que introduce la buena fe como cláusula general". 
denomina el "efecto sándwich", pues de una parte, quien es identificado como proveedor de un servicio o empresario está sujeto a las condiciones contractuales impuestas por un tercero, cuyo poder negociador y, a menudo, acceso a la información, produce el mismo desequilibrio que en las relaciones entre empresarios y consumidores. Como advierte el citado Vicent Chuliá: "De esta forma, las grandes empresas (a veces multinacionales), podrán imponer sus condiciones generales a las numerosas pequeñas y medianas empresas y microempresas españolas (partiendo de la tesis que estas no necesitan la protección de la LCGC en punto al contenido del contrato), mientras que éstas PYMES o microempresas (que constituyen más del 95\% de las empresas españolas) tendrán que respetar el régimen más riguroso de la $L C G C$ y $L G D C U$ en sus relaciones con los consumidores. Es lo que podriamos denominar el efecto sándwich"ll.

Estas conclusiones son rápidamente trasladables a la realidad chilena. Desde luego, especialmente a la actividad bancaria, en la que pequeños empresarios negocian en condiciones desventajosas en relación con un consumidor final, encontrándose en la mayoría de los casos en situaciones análogas. Pero hay otras actividades de especial relevancia económica en la vida nacional, en la que las condiciones generales, a menudo abusivas, son impuestas a pequeños o medianos empresarios que, en determinadas hipótesis pueden verse gravemente afectados y perjudicados por el desamparo normativo en el que se encuentran ${ }^{12}$.

\section{BIBLIOGRAFÍA}

- Aedo Barrena, Cristián (2008): "Cargas o deberes en la posición contractual del acreedor, con especial referencia a su mora de recibir", en Alejandro Guzmán Brito (editor científico), Colección de Estudios de Derecho Civil en homenaje a la Profesora Inés Pardo de Carvallo, Valparaíso: Ediciones Pontificia Universidad Católica del Valparaíso.

- Blanco Pérez-Rubio, Lourdes (1997), "La posible eficacia directa horizontal de la directiva 93/13 sobre cláusulas abusivas en los contratos celebrados con consumidores (a propósito de las Sentencias del Tribunal Supremo de 8 y 20 de noviembre de 1996", Estudios sobre consumo, 41.

VICENT (2004) 55.

12 Por eso, atendiendo especialmente a la realidad chilena, a las redes de contratación que la actividad minera desenvuelve, hemos propuesto en otro lugar y desde otra perspectiva, una revisión del concepto de la responsabilidad contractual y de la posición del acreedor en el contrato. Sobre este tema véase nuestro trabajo Aedo Barrena, Cristián (2008): "Cargas o deberes en la posición contractual del acreedor, con especial referencia a su mora de recibir", en Alejandro Guzmán Brito (editor científico), Colección de Estudios de Derecho Civil en homenaje a la Profesora Inés Pardo de Carvallo, Valparaíso: Ediciones Pontificia Universidad Católica del Valparaíso, pp. 281-304. 
- Pizarro Wilson, Carlos (2007): "El fracaso de un sistema. Análisis empírico y dogmático del control de cláusulas abusivas en contratos por adhesión", Revista de Derecho, vol. XX, 2

- Sandoval López, Ricardo (2003): Contratos mercantiles, Santiago: Editorial Jurídica de Chile

- (2004): Las reformas introducidas por la Ley $N^{\circ} 19.955$, de 14 de julio de 2004 a la Ley $N^{\circ} 19.496$, sobre protección de los derechos de los consumidores, Santiago: LexisNexis

- Vicent Chuliá, Francisco (1995), "Doctrina, Ciencia de la legislación e institucionalización del Derecho mercantil en la última década", en AA.VV., Estudios de Derecho Mercantil en homenaje al Profesor Manuel Broseta Pont, Valencia: Tirant Lo Blanch, vol. III

(2004): "Condiciones generales de la contratación y condiciones abusivas bancarias", Revista de Derecho patrimonial, 13. 